\title{
Pemodelan Neutral Point Clamped-Multilevel Inverter Tiga Fasa Menggunakan Metode Phase Disposition Pulse Width Modulation
}

\author{
Harris Semendawai, Tole Sutikno \\ Program Studi Teknik Elektro, Fakultas Teknologi Industri, Universitas Ahmad Dahlan \\ Kampus 3, Jln. Prof. Dr. Supomo, Janturan, Yogyakarta 55164 \\ e-mail : semendawai3@gmail.com, tole@ee.uad.ac.id
}

\begin{abstract}
The inverter technology has grown rapidly and widely that used in the industrial and the commercial application. One of those improvements an inverter is a discharge waveform that called the multilevel inverter (MLI). The multilevel Inverter (MLI) can be decreasing load of the switching component because the generator wave generated low frequency and AC voltage within capability output. In this work is made the three-phase of multilevel inverter (MLI) simulation by Matlab / Simulink tools. The process is used the multilevel inverter (MLI) topology that provided Neutral Point Clamped (NPC) and Phase Disposition Pulse Width Modulation (PDPWM) method to get a modulated waveform and AC voltage within the sine wave phase. This analysis is done successfully the three-phase NPC-MLI series simulation by wave level varieties in output wave phase. The result is shown the $A C$ voltage wave that carried by phases of the three wave level and the voltage phases of five wave level.
\end{abstract}

Keywords: Multilevel inverter; Neutral point clamped; Phase disposition pulse width modulation.

\section{Abstrak}

Teknologi inverter telah berkembang pesat dan luas yang digunakan dalam industri dan aplikasi komersial. Salah satu pengembangan inverter adalah bentuk gelombang keluaran yang disebut Multilevel Inverter (MLI). Multilevel Inverter (MLI) dapat mengurangi beban komponen Switching karena gelombang generator menghasilkan frekuensi rendah dan tegangan AC dalam keluaran yang diinginkan. Dalam karya ini dibuat simulasi tiga fase Multilevel Inverter (MLI) oleh perangkat lunak MATLAB/Simulink. Proses ini menggunakan topologi Multilevel Inverter (MLI) yang disajikan dengan metode Neutral Point Clamped (NPC) dan Phase Disposition Pulse Width Modulation (PDPWM) untuk mendapatkan bentuk gelombang termodulasi dan tegangan AC dalam fase gelombang sinus. Analisis ini telah berhasil melakukan simulasi rangkaian NPC-MLI tiga fase oleh bermacam-macam tingkat gelombang dalam fase gelombang keluaran. Hasil yang diperoleh berupa gelombang tegangan AC yang dibentuk oleh per-fase dengan 3 tingkat gelombang dan fase tegangan dengan 5 tingkat gelombang.

Kata kunci: Multilevel inverter; Neutral point clamped; Phase disposition pulse width modulation.

\section{Pendahuluan}

Saat ini banyak teknologi yang digunakan dalam ruang lingkup konversi tegangan antara lain converter dan inverter. Converter adalah pengkonversian tegangan dari tegangan bolak balik atau AC ke tegangan searah atau DC. Berbeda dengan converter, inverter merupakan pengkonversian tegangan DC ke tegangan AC. Inverter adalah salah satu jenis pengkonversian tegangan yang sering digunakan dalam perangkat pendukung sumber tegangan. Salah satu contoh perangkat pendukung sumber tegangan tersebut adalah sistem alternatif pengganti sumber listrik sementara atau sering dikenal sebagai Uninterruptible Power Supply (UPS). Selain itu, inverter sangatlah berperan penting dalam kehidupan masyarakat saat ini baik dibidang industri maupun pemanfaatan energi yang terbarukan. Pada industri, inverter digunakan untuk pengendalian kecepatan motor. Pada pemanfaatan energi terbarukan, inverter berperan penting dalam proses pemanfaatan teknologi panel surya. Teknologi inverter sebagai rangkaian 
pendukung sumber tegangan banyak mengalami pengembangan dan perbaikan. Pengembangan dan perbaikan dari inverter tersebut dilakukan pada metode maupun sistem yang digunakan untuk menghasilkan keluaran dengan kualitas tinggi sebagai penyedia tegangan peralatan listrik. Pengembangan dari inverter banyak dilakukan salah satunya adalah pengembangan dari sisi gelombang keluaran yang dihasilkan [1]. Pada sebuah inverter bentuk keluaran yang dihasilkan memiliki dua buah tingkatan gelombang keluaran. Pengembangan dari inverter pada sisi gelombang keluaran yaitu Multilevel Inverter.

Multilevel Inverter (MLI) mampu menghasilkan bentuk gelombang berkualitas tinggi dengan tegangan rendah. Selain memanfaatkan tegangan rendah, MLI juga mengurangi frekuensi beralih yang berkaitan dengan pensakelaran [2][3]. Pada prosesnya, MLI menghasilkan keluaran berupa gelombang bertingkat yang secara keseluruhan dimodifikasikan lebih unggul kualitasnya dalam mengurangi kebutuhan filter [4]. Ada tiga topologi dari MLI yaitu cascaded $\mathrm{H}$ bridges, flying capacitor [5], dan diode-clamped [6]-[9]. Secara keseluruhan topologi diodeclamped memiliki strutur yang sederhana [10]. Selain topologi, MLI juga memiliki metode pensakelaran pada rangkaiannya. Salah satu dari metode pensaklarannya adalah Phase Disposition Pulse Width Modulation (PDPWM)[11][12]. Metode PDPWM adalah salah satu strategi modulasi dari perpotongan antara gelombang segitiga dengan gelombang sinus yang menghasilkan pulsa pembangkit [13][14].

Pentingnya sebuah inverter dalam kehidupan sehari-hari baik pada bidang industri maupun bidang pemanfaatan sumber energi terbarukan, maka dilakukan desain simulasi untuk melengkapi informasi. Penelitian yang dilakukan dengan mendesain simulasi dengan NPC-MLI menggunakan metode PDPWM melalui perangkat lunak MATLAB/Simulink.

\section{Metode}

Perancangan dari rangkaian NPC-MLI dimulai dengan merangkai sumber tegangan masukan DC, sinyal pembangkit, rangkaian switching, dan kombinasi output tegangan. Perancangan dari penelitian pada simulasi seperti pada Gambar 1.

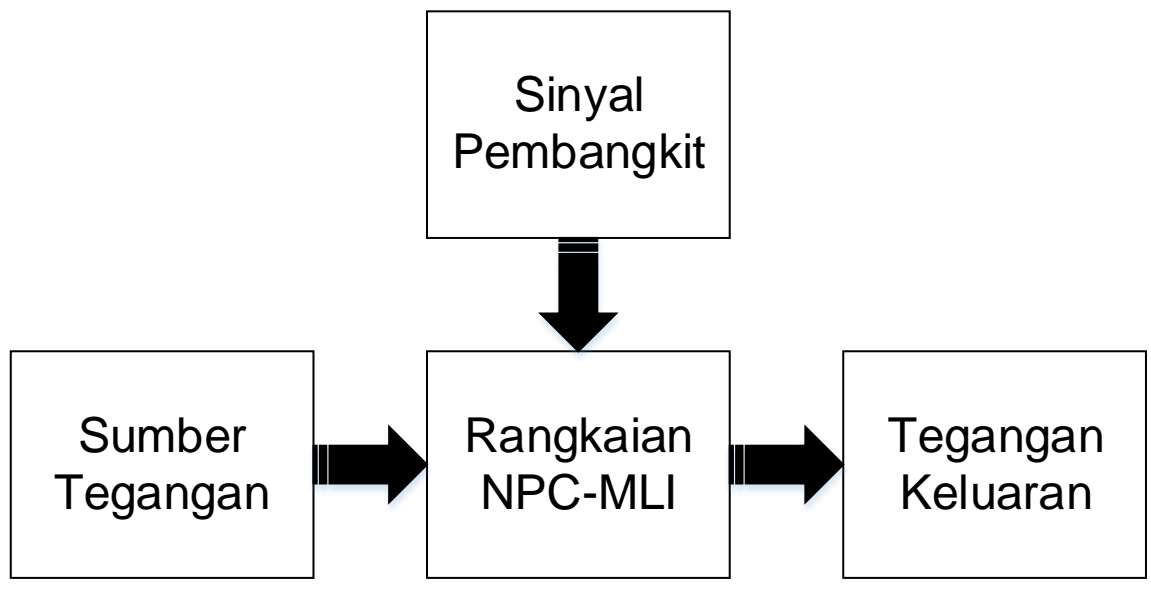

Gambar 1. Diagram blok rangkaian NPC-MLI

Keseluruhan dari rangkaian pada Gambar 1 akan dilakukan simulasi pada aplikasi MATLAB/Simulink seperti pada Gambar 2. Sumber tegangan DC yang digunakan pada rangkaian sebanyak dua buah dengan nilai tegangan yang sama dapat dilihat pada Gambar 3 (a). Sumber tegangan DC tersebut kemudian masuk ke rangkain NPC-MLI yang nantinya akan diubah bentuk tegangannya menyerupai bentuk tegangan AC pada Gambar 4 (a).

Pada proses rangkaian NPC-MLI membutuhkan sinyal pembangkit dimana sinyal pembangkit tersebut berfungsi sebgai sinyal pengendali dari teganan DC yang akan diubah menjadi tegangan AC. Rangkaian pembangkit dapa dilihat pada Gambar 3 (b). Metode yang digunakan pada pembangkitan sinyal tersebut menggunakan metode PDPWM. Setelah melalui proses pembangkitan sinyal dan switching, gelombang keluaran tersebut diperoses untuk dapat ditampilkan bentuk dari gelombang tegangan yang menyerupai tegangan AC pada Simulink. Proses pembentukan tegangan keluaran terbagi menjadi dua bagian yaitu proses pembentukan tegangan per fasa dan proses pembentukan tegangan antar fasa yang dapa dilihat pada Gambar 4 (b). 


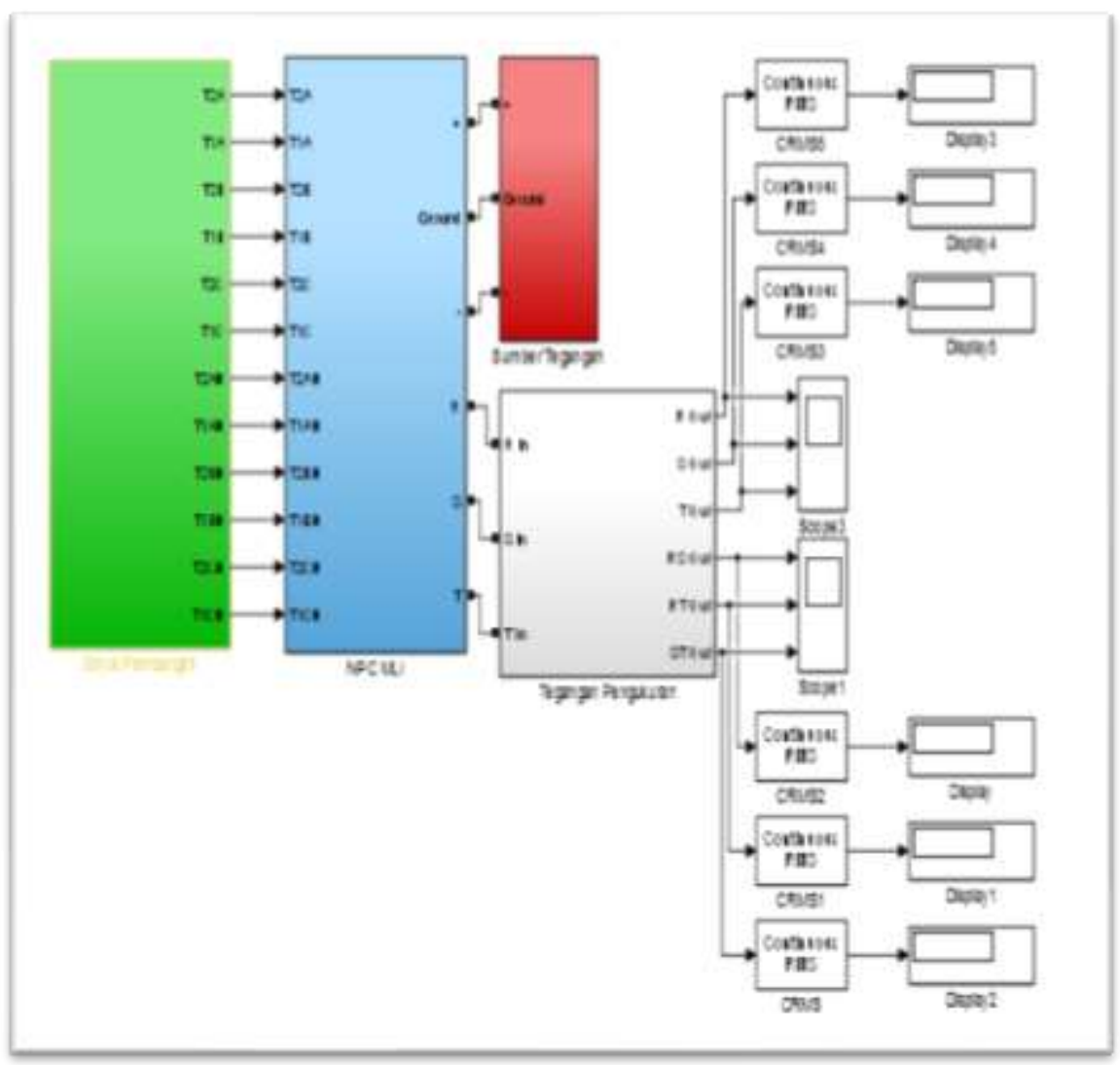

Gambar 2. Rangkaian NPC-MLI secara keseluruhan

Proses pembentukan tegangan dilakukan menggunakan komponen voltage measurement. Komponen voltage measurement pada rangkaian membutuhkan dua buah masukan berupa tegangan positif dan negati. Pada proses pembentukan tegangan per fasa untuk masukan positif digunakan keluaran dari NPC-MLI dan pada masukan negatif mendapat masukan dari ground. Berbeda dengan proses pembentukan tegangan per fasa, semua masukan pada komponen voltage measurement dalam proses pembentukan tegangan antar fasa bersumber dari keluaran rangkaian NPC-MLI.

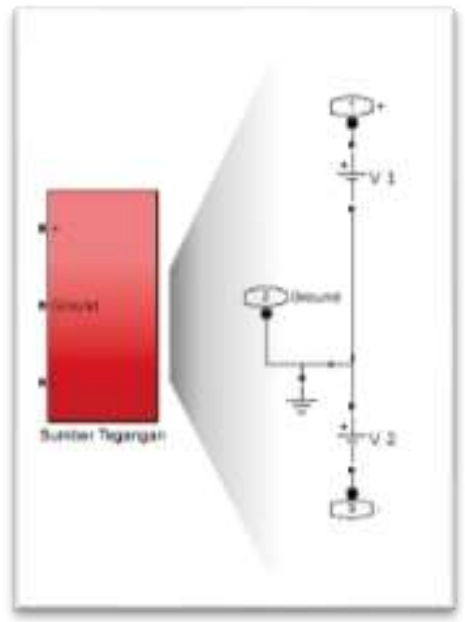

(a)

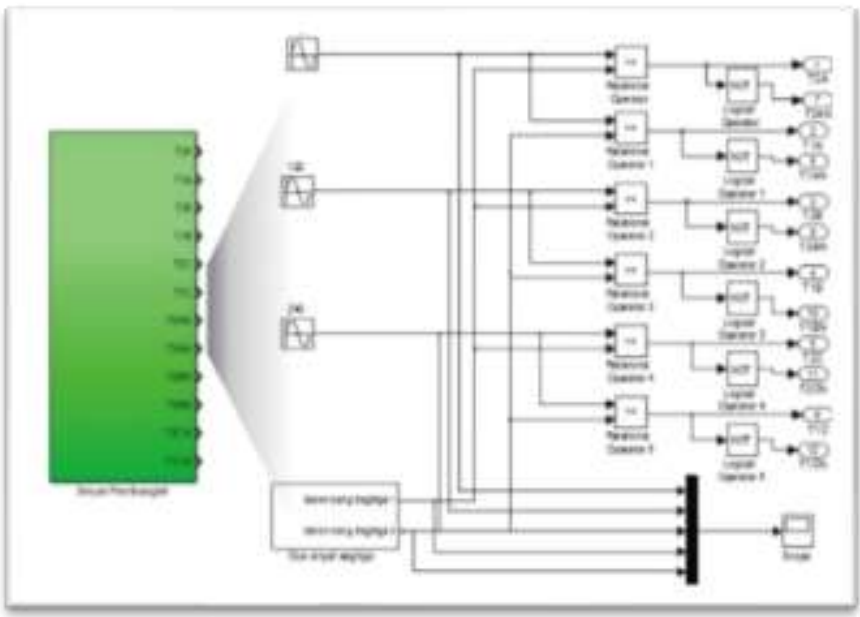

(b)

Gambar 3. Rangkaian, (a) Sumber tegangan, dan (b) Sinyal pembangkit 


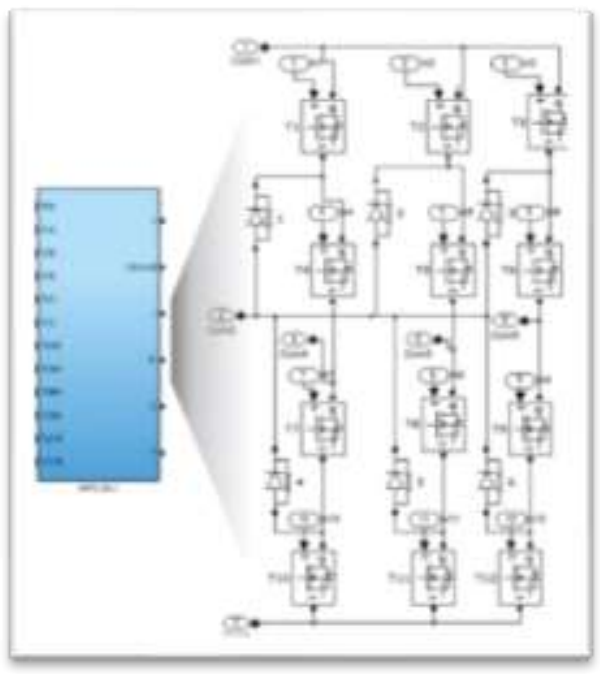

(c)

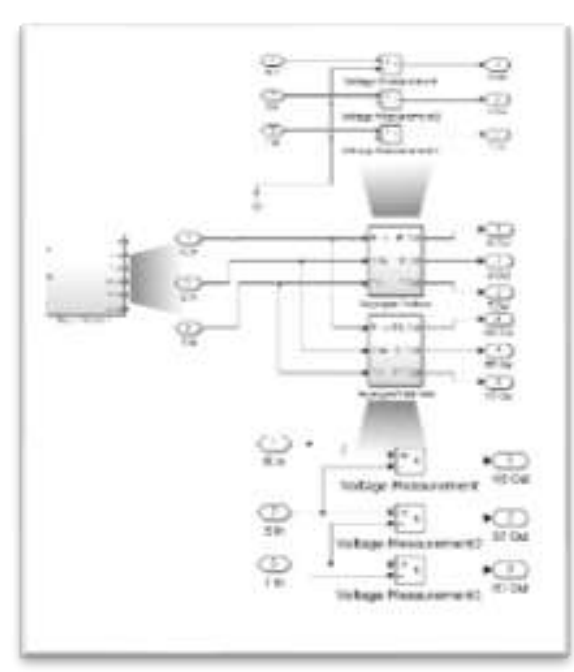

(d)

Gambar 4. Rangkaian, (c) NPC-MLI , dan (d) pembenukan gelombang

Setelah dilakukan perangkaian dari rangkaian secara keseluruhan, dilakukan pengumpulan data berupa :

1. Gelombang pembangkit yang diperoleh dari hasil modulasi dengan metode PDPWM antara 3 buah gelombang sinus dan 2 buah gelombang segitiga.

2. Nilai tegangan dan gelombang keluaran dari NPC-MLI per fasa.

3. Nilai tegangan dan gelombang keluaran dari NPC-MLI antar fasa.

4. Tegangan keluaran ketika diberi tegangan masukan bervasriasi yaitu 100 volt, 150 volt, 200 volt, 250 volt, 300 volt, 350 volt dan 400 volt pada NPC-MLI per fasa maupun antar fasa.

\section{Hasil}

Pada tahap ini yakni dengan melakukansimulasi dari rangkaian yang telah didesain. Hasil yang didapat berupa bentuk gelombang termodulasi. Pada Gambar 5 dan Gambar 6 dihasilkan melalui pengolahan gelombang yang dilakukan pada rangkaian pembangkit.

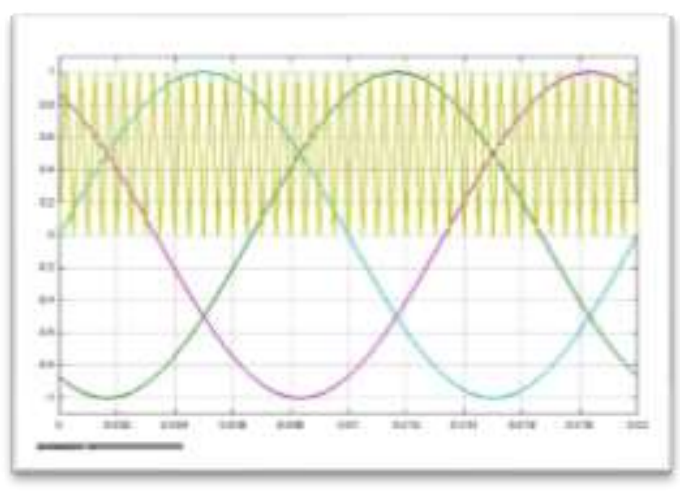

(a)

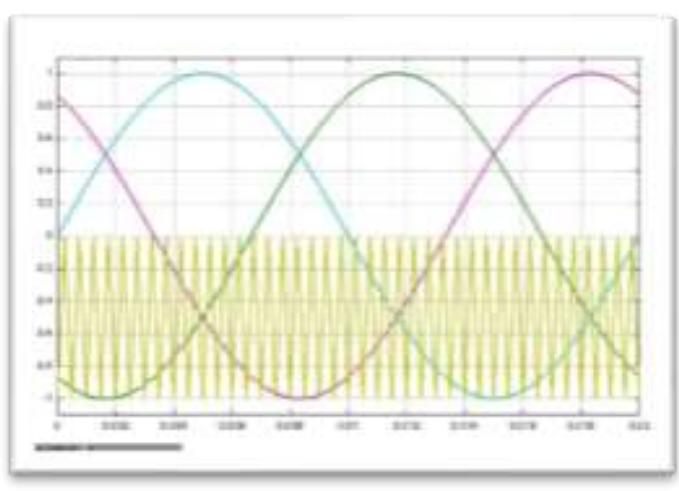

(d)

Gambar 5. (a) Gelombang pembentuk segitiga atas, dan (b) Segitiga bawah, 


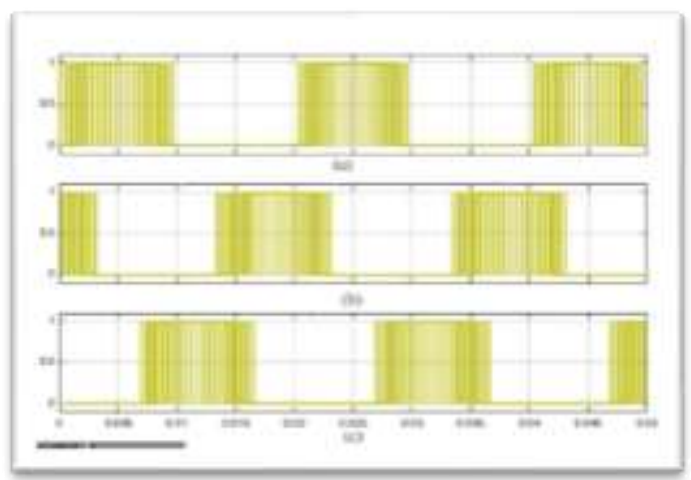

(a)

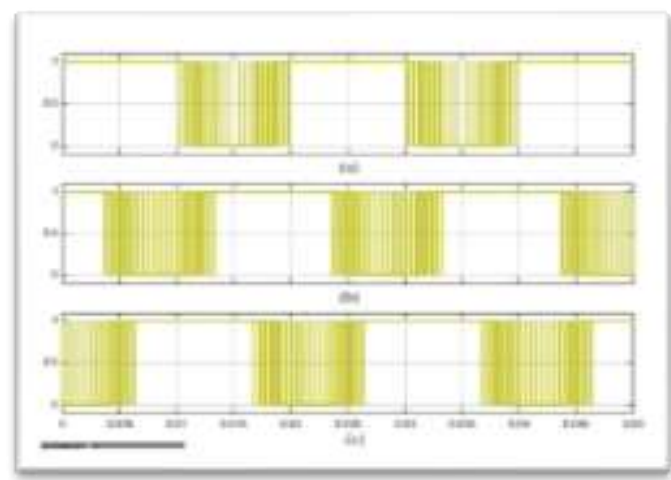

(b)

Gambar 6. Hasil modulasi gelombang (a) Segitiga atas dan (b) Segitiga bawah

Berdasarkan pembentukan gelombang pembangkit menggunakan metode PDPWM pada simulasi yang telah dilakukan menghasilkan bentuk keluaran yang sesuai. Selain bentuk dari gelombang pembangkit yang menggunakan metode PDPWM, gelombang keluaran yang dihasilakn pada Gambar 6 telah membentuk gelombang bertingkat baik seperti pada Gambar 7 (a) maupun Gambar 7(b).

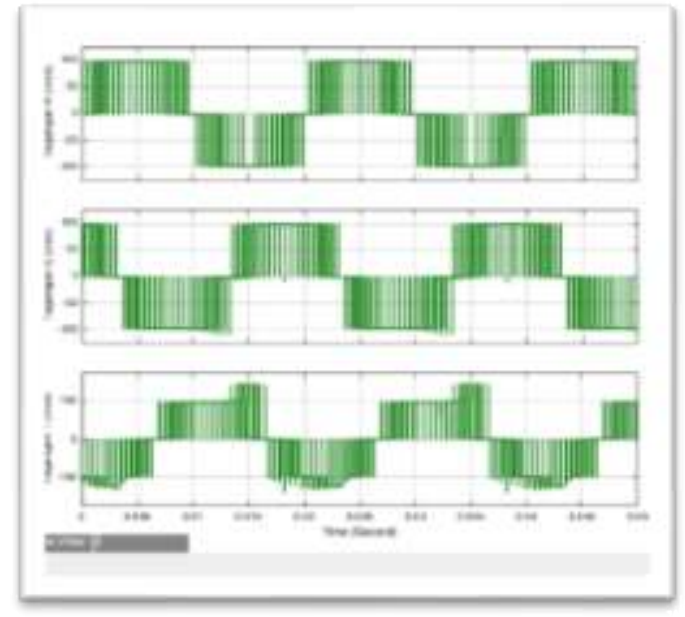

(a)

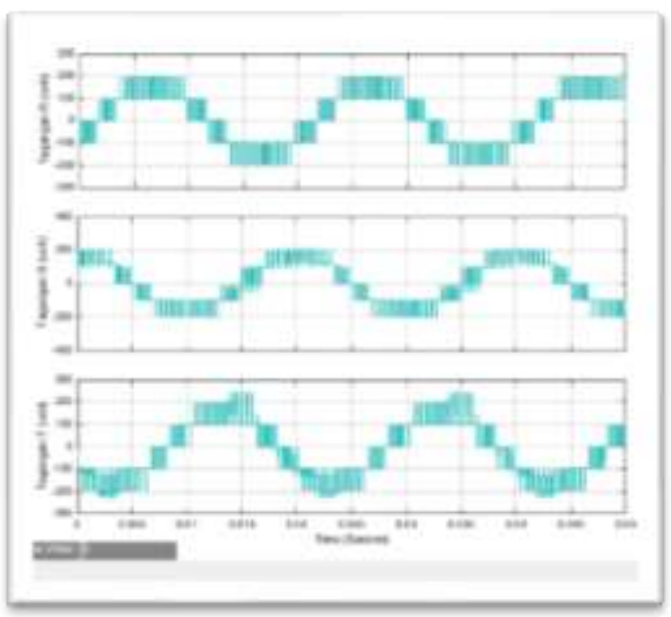

(b)

Gambar 7. Bentuk gelombang keluaran (a) Proses per fasa dan (a) Proses antar fasa

Berdasarkan gelombang keluaran yang didapat niali tegangan dari proses konversi yang disimulasikan dapat di lihat pada Tabel 1 dan Tabel 2.

Tabel 1. Nilai tegangan antar fasa

\begin{tabular}{ccccc}
\hline No & $\begin{array}{c}\text { Masukan } \\
\text { Tegangan } \\
\text { (volt) }\end{array}$ & $\begin{array}{c}\text { Keluaran } \\
\text { Tegangan } R \\
\text { (volt) }\end{array}$ & $\begin{array}{c}\text { Keluaran } \\
\text { Tegangan } \\
\text { (volt) }\end{array}$ & $\begin{array}{c}\text { Keluaran } \\
\text { Tegangan T } \\
\text { (volt) }\end{array}$ \\
\hline 1 & 100 & 78.21 & 78.3 & 85.38 \\
2 & 150 & 118.1 & 118.3 & 128.9 \\
3 & 200 & 158 & 158.2 & 172.5 \\
4 & 250 & 197.9 & 198.1 & 216.1 \\
5 & 300 & 237.8 & 238.1 & 259.6 \\
6 & 350 & 277.7 & 529.6 & 545 \\
7 & 400 & 317.6 & 318 & 345.7 \\
\hline
\end{tabular}


Berdasarkan data pada Tabel 1, setiap keluar pada masing-masing fasa memiliki nilai keluaran yang tidak sama. Perbedaan yang terdapat pada masing-masing fasa tidak terlampau jauh.

Tabel 2. Nilai tegangan antar fasa

\begin{tabular}{ccccc}
\hline No & $\begin{array}{c}\text { Masukan } \\
\text { Tegangan } \\
\text { (volt) }\end{array}$ & $\begin{array}{c}\text { Keluaran } \\
\text { Tegangan } \\
\text { RS (volt) }\end{array}$ & $\begin{array}{c}\text { Keluaran } \\
\text { Tegangan } \\
\text { RT (volt) }\end{array}$ & $\begin{array}{c}\text { Keluaran } \\
\text { Tegangan } \\
\text { (volt) }\end{array}$ \\
\hline 1 & 100 & 123,3 & 130,4 & 134,2 \\
2 & 150 & 118.1 & 118.3 & 202,7 \\
3 & 200 & 158 & 158.2 & 271,1 \\
4 & 250 & 197.9 & 198.1 & 339,6 \\
5 & 300 & 237.8 & 238.1 & 408 \\
6 & 350 & 277.7 & 529.6 & 476,5 \\
7 & 400 & 317.6 & 318 & 545 \\
\hline
\end{tabular}

Keluaran yang tertera pada Table 2 memiliki nilai keluaran yang lebih besar dari keluaran pada Tabel 1. Hal tersebut dikarenakan perbedaan pada proses pembentukan keluaran, sehingga hal tersebutlah yang menjadikan perbedaan.

\section{Kesimpulan}

Pada penelitian ini telah disimulasikan rangkaian MLI tiga fasa dengan topologi NPC serta metode PDPWM (Phase Disposition Pulse Width Modulation) untuk mendapatkan keluaran berupa tegangan AC dan gelombang pembangkit yang menyerupai bentuk gelombang sinus. Proses pembentukan tegangan dibagi menjadi 2 yaitu proses pembentukan per-fasa dan pembentukan antar fasa. Proses pembentukan tegangan per-fasa menghasilkan 3 level gelombang bertingkat dan terjadi penurunan tingkat tegangan proses. Berbeda pada pembentukan tegangan antar fasa, tingkat level keluaran gelombang lebih banyak dari proses pembentukan tegangan per fasa yaitu 5 level dan memiliki peningkatan tegangan proses.

\section{Referensi}

[1] B. A. Yomahudaya et al., "Inverter Satu Fasa Lima Tingkat Berbasis Mikrokontroler ATMega32," vol. 3, no. 2, 2017.

[2] A. S. J. Bitar and I. F. Crowley, "PWM Techniques : A Pure Sine Wave Inverter," p. 91, 2011.

[3] E. A. T. Yuwono and M. Facta, "Inverter Multi Level Tipe Jembatan Satu Fasa Tiga Tingkat," Transmisi, vol. 13, no. 4, pp. 135-140, 2011.

[4] G. K. and R. R. P. B. VeenVani, G.Satheesh, "Space Vector Based Transistor-Clamped Cascaded," vol. 2, no. 5, pp. 1001-1007, 2015.

[5] C. R. Balamurugan, S. P. Natarajan, and R. Bensraj, "Investigations on Three Phase Five Level Diode Clamped Multilevel Inverter," vol. 2, no. 3, pp. 1273-1279, 2012.

[6] A. Nabae, I. Takahashi, and H. Akagi, "A New Neutral-Point-Clamped PWM Inverter," IEEE Trans. Ind. Appl., vol. IA-17, no. 5, pp. 518-523, 1981.

[7] M. M. Shobini, J. Kamala, and R. Rathna, "Analysis and simulation of flying capacitor multilevel inverter using PDPWM strategy," IEEE Int. Conf. Innov. Mech. Ind. Appl. ICIMIA 2017 - Proc., no. Icimia, pp. 91-95, 2017.

[8] Yashobanta Panda, "Analysis of Cascaded Multilevel Inverter Induction Motor Drives," pp. 1-108, 2010.

[9] P. S. Chandrashekhar, "- Neutral Point Clamped ( Npc) Type Multilevel Inverter II," vol. 5, no. 9, pp. 126-128, 2016.

[10] A. D. Matkar and P. M. Joshi, "COMPARATIVE STUDY OF PWM TECHNIQUES FOR DIODE- CLAMPED MULTILEVEL-INVERTER,” vol. 2, no. 6, pp. 73-77, 2015.

[11] P. Panda, P. Agrawal, and V. Puli, "Cascaded H-Bridge Multilevel Inverter for Induction Motor Drives," pp. 260-266, 2014.

[12] G. Vijayalakshmi, "Original Article Development of multi carrier PWM technique for five level voltage source inverter," vol. 5, no. 1, pp. 1-6, 2015. 
Jurnal IImu Teknik Elektro Komputer dan Informatika (JITEKI)

Vol. 4, No. 1, Juni 2018

[13] R. A. Vargas, A. Figueroa, S. E. Deleon, J. Aguayo, L. Hernandez, and M. A. Rodriguez, "Analysis of Minimum Modulation for the 9-Level Multilevel Inverter in Asymmetric Structure," IEEE Lat. Am. Trans., vol. 13, no. 9, pp. 2851-2858, 2015.

[14] S. Himavathi and A. Chitra, "Reduced switch multilevel inverter for performance enhancement of induction motor drive with intelligent rotor resistance estimator," IET Power Electron., vol. 8, no. 12, pp. 2444-2453, 2015. 